\section{The Ets transcription factor Elf5 specifies mammary alveolar cell fate}

Samantha R. Oakes, ${ }^{1,7}$ Matthew J. Naylor, ${ }^{1,2,7}$ Marie-Liesse Asselin-Labat, ${ }^{3}$ Katrina D. Blazek, ${ }^{1}$ Margaret Gardiner-Garden, ${ }^{1}$ Heidi N. Hilton, ${ }^{1}$ Michael Kazlauskas, ${ }^{1}$ Melanie A. Pritchard, ${ }^{4}$ Lewis A. Chodosh, ${ }^{5}$ Peter L. Pfeffer, ${ }^{6}$ Geoffrey J. Lindeman, ${ }^{3}$ Jane E. Visvader, ${ }^{3}$ and Christopher J. Ormandy ${ }^{1,2,8}$

${ }^{1}$ Cancer Research Program, Garvan Institute of Medical Research, Darlinghurst, New South Wales 2010, Australia; ${ }^{2}$ St. Vincent's Hospital Clinical School, Faculty of Medicine, University of New South Wales, Sydney,

New South Wales 2052, Australia; ${ }^{3}$ Victorian Breast Cancer Research Consortium (VBCRC) Laboratory, The Walter and Eliza Hall Institute of Medical Research, Parkville, Victoria 3050, Australia; ${ }^{4}$ Centre for Functional Genomics and Human Disease, Monash Institute of Medical Research, Clayton, Victoria 3168, Australia; ${ }^{5}$ Department of Cancer Biology and Abramson Family Cancer Research Institute, University of Pennslvania,

Philadelphia, Pennsylvania 19104, USA; ${ }^{6}$ AgResearch

Ruakura, Hamilton 3240, New Zealand

Hormonal cues regulate mammary development, but the consequent transcriptional changes and cell fate decisions are largely undefined. We show that knockout of the prolactin-regulated Ets transcription factor Elf5 prevented formation of the secretory epithelium during pregnancy. Conversely, overexpression of Elf 5 in an inducible transgenic model caused alveolar differentiation and milk secretion in virgin mice, disrupting ductal morphogenesis. $\mathrm{CD}^{+} 1^{+}$luminal progenitor cells accumulated in Elf5-deficient mammary glands and were diminished in glands with Elf5 overexpression. Thus Elf5 specifies the differentiation of $\mathrm{CD61}^{+}$progenitors to establish the secretory alveolar lineage during pregnancy, providing a link between prolactin, transcriptional events, and alveolar development.

Supplemental material is available at http://www.genesdev.org.

Received September 11, 2007; revised version accepted December 21, 2007.

Mammary morphogenesis occurs predominantly after birth and is coordinated with reproductive events by shared hormonal cues (Neville et al. 2002). These cues initiate interacting programs of altered gene expression, cell division, and differentiation within the stem and

[Keywords: Elf5; Ets transcription factor; mammary; alveolar; cell fate; differentiation]

${ }^{7}$ These authors contributed equally to this work.

${ }^{8}$ Corresponding author.

E-MAIL c.ormandy@garvan.org.au; FAX 61-2-92958321.

Article is online at http://www.genesdev.org/cgi/doi/10.1101/gad.1614608. progenitor cell hierarchy. The precise location, arrangement, composition, and regulation of these programs is the subject of intense interest (Kordon and Smith 1998; Smalley and Ashworth 2003; Shackleton et al. 2006; Stingl et al. 2006).

We showed previously that the transcription factors Elf5 (Zhou et al. 1998; Oettgen et al. 1999) and Gata3 may lie downstream from the prolactin receptor (Ormandy et al. 2003; Harris et al. 2006). Gata3 is essential for ductal and alveolar morphogenesis via regulation of the stem and $\mathrm{CD} 61^{+}$progenitor cell pools (Kouros-Mehr et al. 2006; Asselin-Labat et al. 2007). Elf5 is required for placentation, and as a consequence the knockout $\left(E l f 5^{-/-}\right)$conceptus is nonviable by day 7.5-8.5 of pregnancy (Donnison et al. 2005). Elf5 heterozygote mice $\left(E l f 5^{+/-}\right)$show defective lobuloalveolar development and reduced milk secretion during pregnancy (Zhou et al. 2005). Retroviral re-expression of Elf5 in Prlr knockout mammary glands rescued alveolar morphogenesis in a dose-dependent fashion (Harris et al. 2006). Elf5 can trans-activate the whey acidic protein (Wap) promoter, a component of milk (Thomas et al. 2000).

Here we show that Elf5 is essential for normal alveolar development and lactation due to regulation of the $\mathrm{CD} 61^{+}$progenitor cell population, establishing the links between hormonal regulation, gene expression, progenitor cell activity, and biological function that result in milk being available to the neonate.

\section{Results and Discussion}

Elf5 is essential for the differentiation phase of alveolar development during pregnancy

Elf5-null $\left(E l f 5^{-/-}\right)$embryos were generated by tetraploid embryonic stem (ES) cell rescue to avoid the placentation defect (Donnison et al. 2005), and post-pubertal $E_{1 f 5^{-/}}$mammary epithelium was serially transplanted to wild-type $\mathrm{Rag}^{-1-}$ hosts. More than $95 \%$ of transplants successfully engrafted, and all that did so displayed normal ductal elongation, bifurcation, and sidebranching (Fig. 1A). FACS analysis of freshly isolated epithelial cells $\left(\right.$ Lin $\left.^{-}\right)$from Elf5 $5^{-1-}$ mammary transplants revealed no difference in the proportion of CD $24^{+} \mathrm{CD} 29^{\mathrm{hi}}$ double-positive cells enriched for mammary stem cells (MaSCs) (Shackleton et al. 2006) compared with control mammary transplants (wild type). Transplantation at limiting dilution revealed that Elf5 ${ }^{-/-}$MaSCs had a similar repopulating potential to wild-type MaSCs (data not shown). Thus loss of Elf5 did not affect the proportion or self-renewal capacity of MaSCs or the process of ductal morphogenesis.

We collected Elf5 ${ }^{-/}$mammary transplants during pregnancy (Fig. 1A). Lobuloalveolar development was severely impaired from early pregnancy (Fig. 1A) and milk production was lost in Elf5 $5^{--}$animals. These results were similar to those seen in Prlr ${ }^{-/}$glands and in a few of the most affected Elf5 $5^{+-}$animals (Zhou et al. 2005). The number of Ki67-positive cells was reduced in Elf5 ${ }^{-/}$ mammary transplants compared with wild-type transplants at $4.5 \mathrm{~d}$ post-coitus $(\mathrm{dpc})(7.4 \%$ vs. $12.8 \%$, $P=0.07)$ and $6.5 \mathrm{dpc}(6.3 \%$ vs. $14.3 \%, P<0.01)($ Fig. $1 \mathrm{~B})$, but ongoing proliferation in $E l f 5^{-/}$mammary epithelium showed that Elf5 is not essential for the prolifera- 


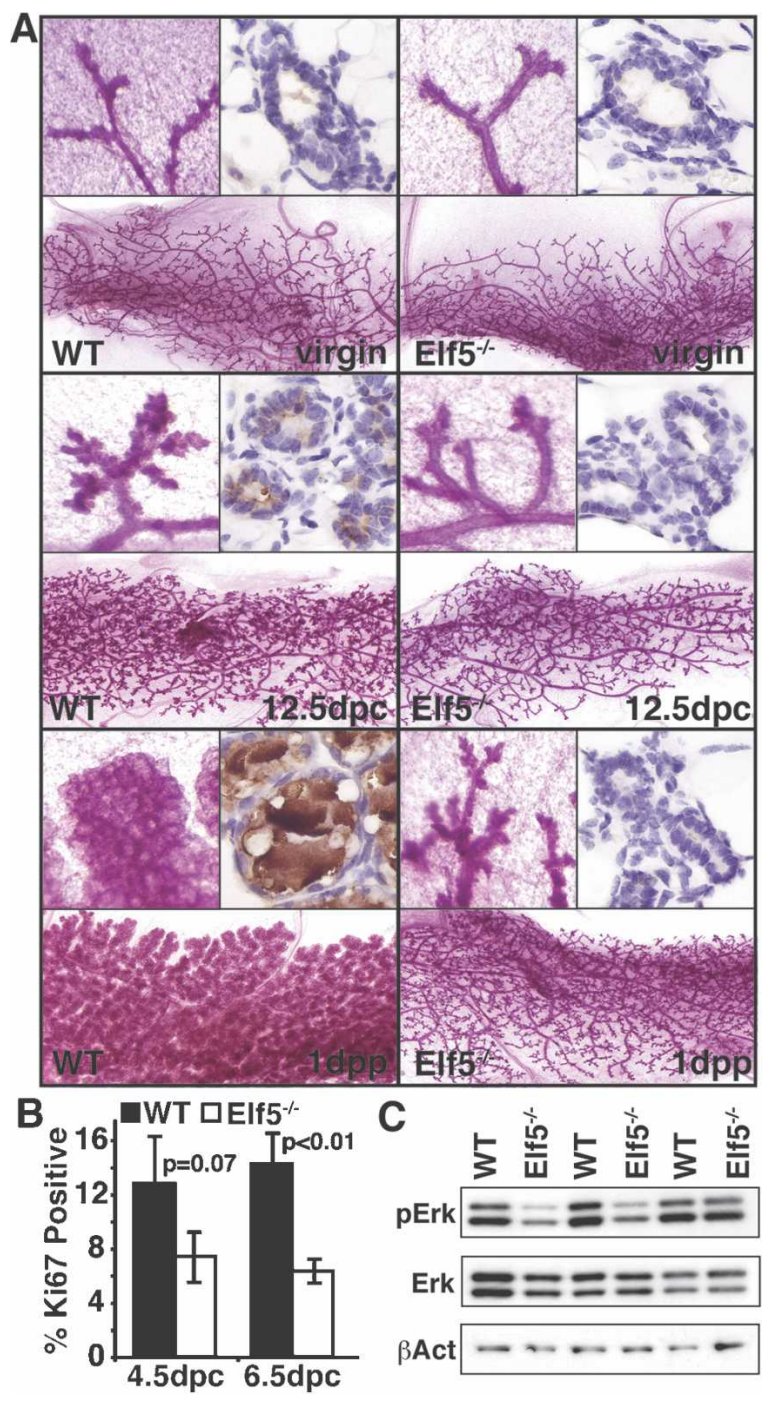

Figure 1. Deletion of Elf5 results in failed alveolar differentiation. (A) Mammary gland morphology from wild-type (left panels) and Elf5 $5^{-1-}$ (right panels) mammary transplants collected from virgin (top third), 12.5-dpc (middle third), and 1-d-post-partum (bottom third) hosts. Low-power (bottom) and high-power (top left) wholemounts and mammary epithelium stained with an antibody against milk proteins (brown, top right) counterstained with haematoxylin are illustrated. $(B)$ The percentage of cells stained positive for an antibody against the proliferation antigen Ki67 in mammary transplants with wild type (black bars) and Elf5 ${ }^{-1-}$ (white bars) epithelium collected at 4.5 and $6.5 \mathrm{dpc}$. (C) Representative Western blot of phosphorylated Erk (pErk) and Erk (Erk) protein levels in Elf5 $5^{-/}$and wild-type mammary transplants at $4.5 \mathrm{dpc}$.

tion of all epithelial cells, indicating a specific target subpopulation. The Mapk pathway is involved in prolactin-driven epithelial proliferation /Chilton and Hewetson 2005). Erk phosphorylation was significantly reduced in Elf5 $5^{-/-}$transplants compared with wild type at $4.5 \mathrm{dpc}(2.0 \pm 0.5$ vs. $2.6 \pm 0.4 ; n=5 ; P=0.02)$ and showed a trend for reduced activation at $6.5 \mathrm{dpc}$ $(1.7 \pm 0.3$ vs. $2.3 \pm 0.5 ; n=5 ; P=0.09)$, indicating modulation of the Mapk pathway by Elf5 (Fig. 1C).

We examined the changes in global patterns of gene expression between five-paired Elf5-null and wild-type mammary transplants at $4.5 \mathrm{dpc}$ using Affymetrix oligo- nucleotide arrays. The expression of several known mediators of mammary gland development were reduced in Elf5 ${ }^{-/-}$transplants (Supplemental Table 1). These genes may be either directly transcribed by Elf5 or represent targets of genomic regulatory networks activated by Elf5.

Forced Elf5 expression resulted in alveolar differentiation of virgin mammary epithelium and precocious milk secretion during pregnancy

We next examined whether increased Elf5 expression was sufficient to induce the differentiation of virgin mammary epithelium. We crossed the MTB mouse, which expresses the rtTA protein under the mouse mammary tumor virus promoter (Gunther et al. 2002), with a transgenic animal that placed an Elf5-IRES-EGFP construct under the control of the Tet operator, allowing forced Elf5 and EGFP coexpression in the mammary epithelium in response to doxycycline (Dox). Robust EGFP fluorescence was observed throughout the mammary epithelium of Elf5 $\mathrm{Tg}^{\mathrm{Elf5} /+/ M T B /+}$ bitransgenic mice $(\mathrm{Tg})$ in response to Dox (Fig. 2A, Tg + Dox). No EGFP fluorescence was detectable in untreated Tg mice (Fig. 2A, TgDox). As no differences in mammary phenotype were observed between untreated Elf5 $5^{E l f 5 /+/ M T B /+}$ mice and Dox-treated monotransgenic littermates lacking either the MTB or the Elf5 construct (data not shown), the latter were used as controls to reduce the number of mice used in breeding for these experiments and to allow for the inclusion of Dox-treated control animals.

Mice were treated with Dox during the ductal morphogenesis phase of development. Glands collected from 9 -wk-old Tg mice after 3 wk of Dox treatment showed a 7.6-fold increase in the mRNA expression of Elf5 compared with controls $(P=0.02)$ (Fig. 2B,C). This increase in Elf5 expression in virgin mice treated with Dox was less than that of wild-type animals at mid-pregnancy $(P=0.07)$ (Fig. 2B). Increased Elf5 expression resulted in a 12.3 -fold increase in $\beta$ Casein and a 7.2 -fold increase in Wap mRNA expression compared with control mice $(P=0.15$ and $P=0.04$, respectively) (Fig. 2C). In addition, we observed a dramatic increase in the levels of $\beta$ Casein protein (Fig. 2D). Concomitantly, forced Elf5 expression resulted in the formation of small alveoli along the ducts (Fig. 2A, TEBs), and we observed that the ducts proximal to the nipple were distended by accumulated milk (Fig. 2A [ducts], E [insets]). The alveoli of Dox-treated Tg mice expressed EGFP indicative of robust Elf5 expression.

Ductal elongation was slower in Dox-treated Tg mice compared with controls. The epithelium in 7-wk-old Tg mice treated with Dox for 1 wk had just reached the centrally located lymph node, in contrast to control mice, where the epithelium has passed the lymph node (data not shown). This effect was more pronounced in 9-wk-old Tg mice treated with Dox for 3 wk (Fig. 2E, top panels). BrdU (5-bromo-2'-bromodeoxyuridine) immunohistochemistry demonstrated that fewer cells were proliferating in terminal end buds (TEBs) and ducts of Doxtreated Tg mice compared with control, providing an explanation for the retarded ductal elongation (data not shown). Histological examination demonstrated that aberrant Tg TEBs had lost both the cap and body cell layers and their directional appearance (Fig. 2E, third row). Whole-mount and H\&E histology showed the presence of alveoli within the TEBs (Fig. 2E, middle panels). Using immunofluorescence to antibodies against the polariza- 

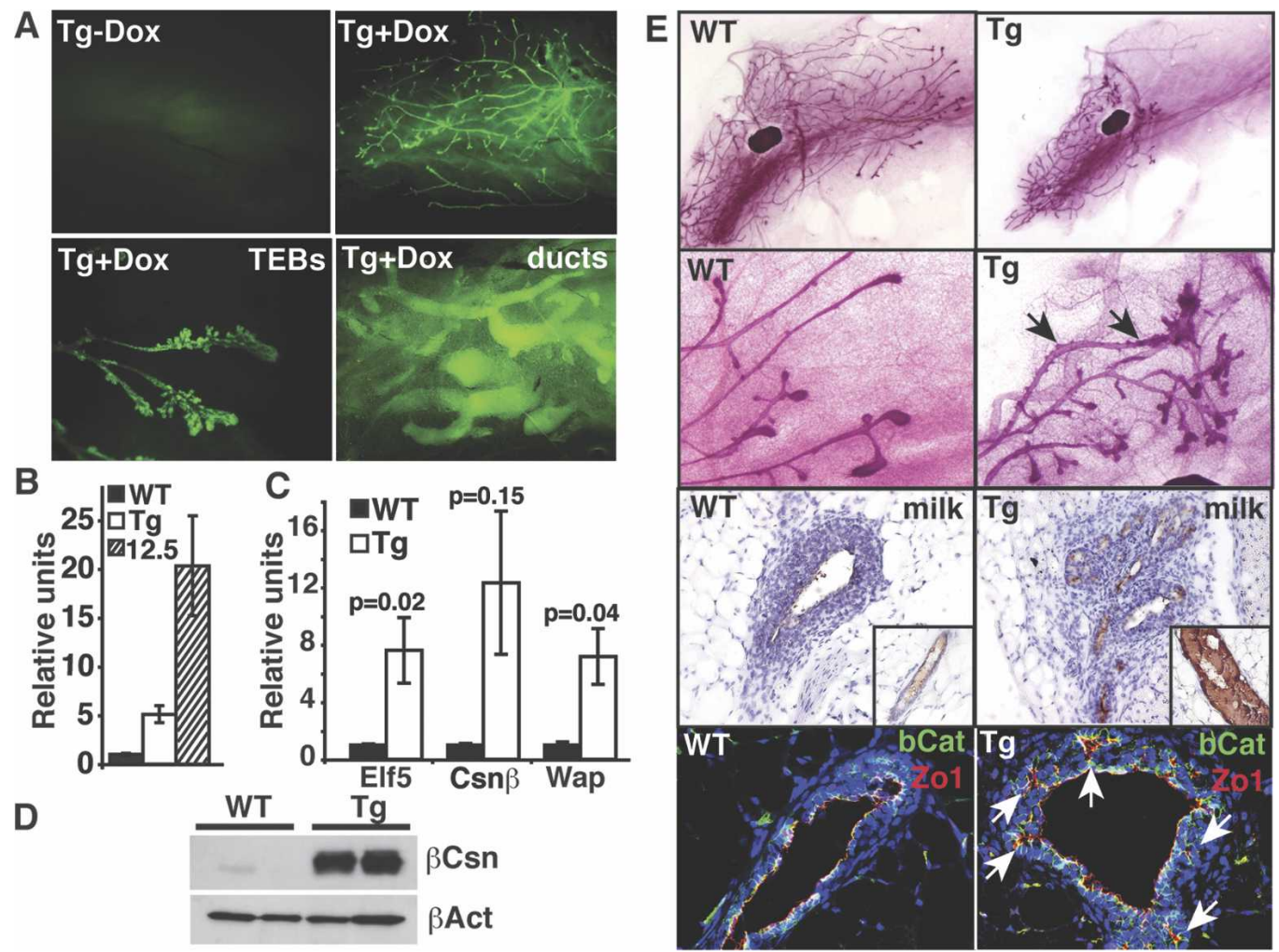

Figure 2. Forced Elf5 expression drives alveolar cell differentiation in virgin ductal epithelium and TEBs. (A) Dark-field images showing EGFP expression in mammary whole-mounts from 9-wk-old control $\mathrm{Tg}$ mice ( $\mathrm{Tg}-\mathrm{Dox}$ ) and $\mathrm{Tg}$ mice after 3 wk of Dox treatment (Tg + Dox). Robust EGFP expression was observed in TEBs at the ends of the epithelium and the distended ducts closest to the nipple (ducts). (B) Relative expression of Elf5 mRNA in 9-wk-old wild-type (black bars) and Tg (white bars) treated with Dox for 3 wk, and wild-type mice at 12.5 dpc (12.5, patterned bars). (C) Relative expression of Elf5, $\beta$ Casein, and Wap mRNA in 9-wk-old wild-type (black bars) and Tg (white bars) mice treated for 3 wk with Dox. (D) $\beta$ Casein $(\beta C s n)$ and $\beta$ Actin ( $\beta$ Act) protein levels in 9-wk-old wild-type (black bars) and Tg (white bars) mice after 3 wk of Dox treatment. (E) Mammary whole-mount morphology from Dox-treated wild-type (left panels) and Tg (right panels) mice collected after 3 wk (low power, top row; high power, second row). Alveolar buds from ducts from Tg mice are illustrated (black arrows). (Third row) TEBs stained with an antibody against milk proteins (milk). (Third row, insets) Milk expression in the ducts proximal to the nipple is also illustrated. The expression of $\beta$ Catenin ( $\beta$ Cat, Cy2 green) and Zol (Cy3, red) in the TEBs from 9-wk wild-type and Tg mice treated with Dox for 3 wk, counterstained with ToPro3 for nuclei (blue). (White arrows) Aberrant alveolar buds.

tion markers Zo1 and $\beta$ Catenin, we observed multiple small polarized alveoli that had formed around the entire perimeter of the TEBs in Dox-treated Tg mice (Fig. 2E, white arrows in bottom panels), not observed in control TEBs (Fig. 2E, bottom panels). Thus forced Elf5 expression inhibited cell proliferation and ductal elongation in virgin animals by inducing alveolar differentiation and secretory activation in the TEBs.

Endogenous Elf5 levels increased greatly during pregnancy and reached maximum levels during lactation (Harris et al. 2006). Tg or control mice were treated with Dox either 3 wk prior to mating, or on the day of conception, and glands were collected at $12.5 \mathrm{dpc}$. Dox treatment of $\mathrm{Tg}$ mice prior to mating resulted in a 2.6-fold increase in the expression of Elf5 mRNA compared with control animals $(P=0.01)$ (Fig. 3A). We observed no morphological changes in the appearance of developing alveoli; however, $\beta$ Casein and Wap mRNA expression was increased by 2.8 -fold and 2.6-fold, respectively, over control mice $(P=0.01$ and $P=0.04)$ (Fig. 3A). Western analysis of $\beta$ Casein protein confirmed these findings (Fig. 3B). In $\mathrm{Tg}$ animals treated with Dox from mating, we observed a lesser increase in $\beta$ Casein mRNA and protein (data not shown), and in animals analyzed at term, the difference in $\beta$ Casein levels between control and treat- ment groups was small. Therefore, endogenous Elf5 is present at limiting levels for $\beta$ Casein production during the first half of pregnancy, but endogenous levels rise during pregnancy to the point that forced expression has no additional effect.

To investigate the effects of forced Elf5 expression during involution, Tg or control mice were treated with Dox from mid-pregnancy. Dams nursed pups for $7 \mathrm{~d}$ prior to

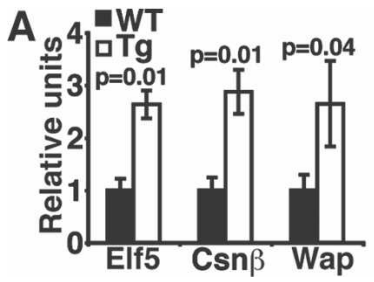

B

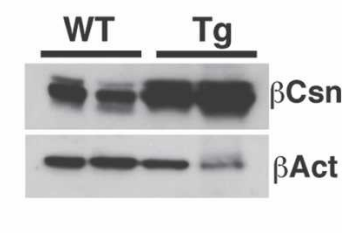

Figure 3. Forced Elf5 expression results in precocious milk secretion during pregnancy. (A) Relative expression of Elf5, $\beta$ Casein, and Wap mRNA in wild-type (black bars) or Tg (white bars) mammary glands collected from 12.5-dpc mice after Dox treatment from 3 wk prior to the observation of a vaginal plug. $(B) \beta$ Casein $(\beta C$ Cas) and $\beta$ Actin (BAct) protein expression from wild-type and Tg mammary glands collected at $12.5 \mathrm{dpc}$ in mice treated with Dox from $3 \mathrm{wk}$ prior to the observation of a vaginal plug. 
pup removal, and mammary glands were collected $6 \mathrm{~d}$ later. We observed no morphological changes in the mammary glands from Dox-treated Tg mice (Supplemental Fig. 1A) and no changes in $\beta$ Casein mRNA or protein levels (Supplemental Fig. 1C,D). To see if sustained Elf5 expression affected mammary gland development over successive pregnancies, $\mathrm{Tg}$ mice were treated with Dox continuously through two pregnancies, and mammary glands were collected at day 14 involution (data not shown). Dox-treated Tg mice successfully nursed their pups on each pregnancy, and the mammary epithelium displayed a normal architecture, indicating that sustained Elf5 expression does not grossly interfere with the remodeling capacity of the mammary gland.

\section{Elf5 drives alveolar cell maturation from luminal cell progenitors}

Elf5 may specify secretory alveolar cell fate by modulating a luminal mammary progenitor cell population. FACS analysis of freshly isolated Lin ${ }^{-}$epithelial cells (AsselinLabat et al. 2007) revealed no difference in the proportion of luminal progenitor cells $\left(\mathrm{CD} 24^{+} \mathrm{CD} 29^{\mathrm{lo}} \mathrm{CD} 61^{+}\right)$in virgin $E l f 5^{-/-}$mammary transplants compared with controls (Fig. 4B). We observed a significant accumulation of luminal progenitor cells in Elf5 $5^{-/}$transplants at $12.5 \mathrm{dpc}$ $(43,967 \pm 8660 ; 57.1 \%)$ and $18.5 \mathrm{dpc}(51,861 \pm 18,216$; $87.4 \%)$ compared with wild-type transplants $(6532 \pm 2395$; $3.4 \%, P<0.05$ and $11,841 \pm 4114 ; 3.2 \%, P<0.01$, respectively) (Fig. 4A,B). We also investigated the proportion of luminal progenitors in Elf5 heterozygous $\left(E l f 5^{+/-}\right)$mice.
The proportion of luminal progenitors was increased in $E l f 5^{+/-}$glands compared with wild type at $12.5 \mathrm{dpc}$ and $18.5 \mathrm{dpc}(23,524 \pm 2390$ vs. $6424 \pm 844 ; 52.4 \%$ vs. $7.8 \%$, $P<0.05$ and $24,153 \pm 2539$ vs. $10,643 \pm 3110 ; 50.3 \%$ vs. $10.9 \%, P<0.01$, respectively) (Fig. 4C). Thus, loss of Elf5 results in a block in the differentiation of $\mathrm{CD} 61^{+}$luminal progenitor cells.

We asked whether the converse was true when we forced the expression of Elf5. Treatment of Tg mice with Dox resulted in an erosion of the luminal progenitor population compared with Dox-treated monotransgenic control mice $(1306 \pm 924 ; 29.7 \%$ vs. $22,162 \pm 3893$; $49.1 \%$ ) (Fig. 4D,E). We next assessed the colony-forming capacity of the epithelial populations isolated from Doxtreated $\mathrm{Tg}$ and control mice using two-dimensional colony-forming assays (Fig. 4F). We observed no difference in the colony-forming capacity of the MaSCs and the mature luminal cells collected from Tg mice compared with the same populations isolated from control mice (Fig. 4F), consistent with our earlier findings. We observed a large decrease in the colony-forming ability of the luminal progenitor population collected from Doxtreated Tg animals, suggesting that forced Elf5 expression results in differentiation of luminal progenitors, thus eroding their number and colony-forming ability. $\mathrm{CD} 61^{+}$luminal progenitor cells have been demonstrated previously to be the precursors of the mature secretory alveolar epithelium (Asselin-Labat et al. 2007). We also showed that forced Elf5 expression results in alveolar differentiation of the virgin epithelium associated with secretory activation. We therefore conclude that Elf5
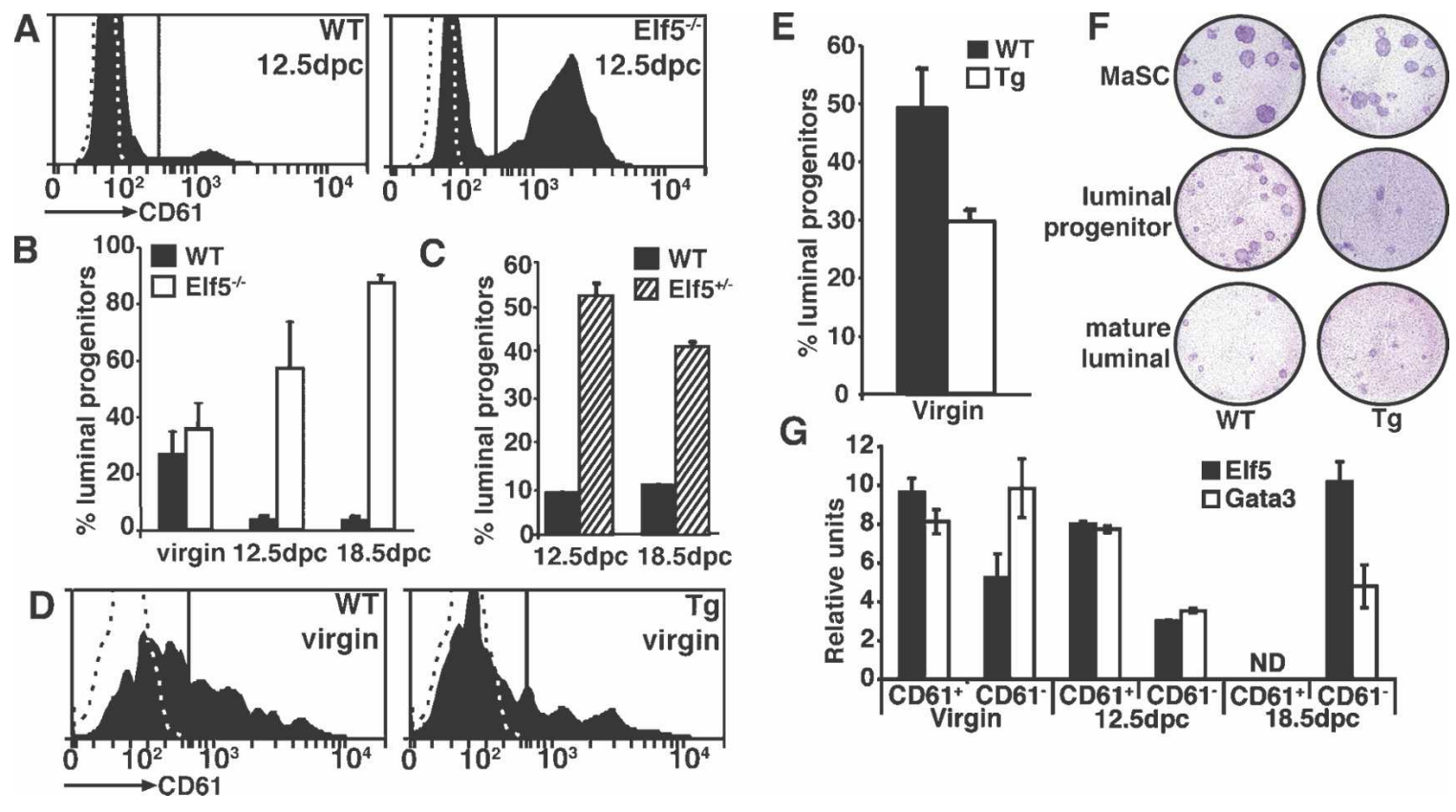

Figure 4. Elf5 drives the differentiation of luminal progenitor cells. $(A)$ Representative FACS profile showing the expression of CD61 in $\mathrm{Lin}^{-} \mathrm{CD} 24^{+} \mathrm{CD} 29^{1 \mathrm{lo}}$ cells in Elf5 $5^{+/+}$and Elf5 $5^{-/}$glands in 12.5-dpc mice. (Dashed line) IgG Isotype control. (B) Bar graph depicting the percentage of luminal progenitor cells in wild-type (black bars) and Elf5 $5^{-1-}$ (white bars) glands in virgin, 12.5-dpc, and 18.5-dpc animals. (C) Bar graph depicting the percentage of luminal progenitor cells in wild-type (black bars) and Elf5 $5^{+/}$(patterned bars) glands in 12.5-dpc and 18.5-dpc mice. (D) Representative FACS profile showing the expression of CD61 in Lin $^{-} \mathrm{CD} 24^{+} \mathrm{CD} 29^{10}$ cells in 10-wk-old wild-type and Tg mice after 4 wk of Dox treatment. (Dashed line) IgG Isotype control. (E) Bar graph showing the percentage of luminal progenitor cells in 10-wk-old wild-type (black bar) and $\mathrm{Tg}$ (white bar) mice after 4 wk of Dox treatment. (F) Colony formation capacity of the MaSC-enriched population $\left(\mathrm{CD} 29^{\mathrm{hi}} \mathrm{CD} 61^{+}\right.$; top panel), the progenitor population $\left(\mathrm{CD} 29^{10} \mathrm{CD} 61^{+}\right.$; middle panel) and the mature luminal population $\left(\mathrm{CD} 29^{10} \mathrm{CD} 61^{-}\right.$; bottom panel) freshly isolated from 10-wk-old wild-type and Tg mice after 4 wk of Dox treatment. (G) Relative expression of Elf5 (black bars) and Gata3 (white bars) mRNA in $\mathrm{CD}^{+} 1^{+}$luminal progenitor and CD61- mature luminal cells isolated from virgin, 12.5-dpc, and 18.5-dpc mice. (ND) Not detected. 
specifies secretory alveolar cell fate from $\mathrm{CD} 1^{+}$luminal progenitor cells. This places Elf5 firmly within a luminal alveolar lineage, as a transcription factor at the origin of a genomic regulatory network responsible for the cell fate specification of secretory alveolar cells.

Although some similarity exists, there are distinct differences between Elf5- and Gata3-deficient mammary glands (Asselin-Labat et al. 2007). Conditional knockout of Gata3 resulted in a similar accumulation of the $\mathrm{CD} 1^{+}$luminal progenitor cells during alveolar morphogenesis (Asselin-Labat et al. 2007), but also defects of the ductal epithelium in virgin mice (Kouros-Mehr et al. 2006; Asselin-Labat et al. 2007), whereas Elf5 effects are restricted to alveolar cell fate specification during pregnancy. Gata3 and Elf5 are expressed mostly in different cell populations. Coimmunofluorescence demonstrated that Elf5-positive luminal epithelial cells were predominantly estrogen receptor-negative (Supplemental Fig. 2A), Gata3-negative (Supplemental Fig. 2B), and frequently BrdU-positive (data not shown). Elf5-expressing cells have a columnar morphology (Supplemental Fig. 2B) similar to that observed for the transcription factor Cebp $\beta$ (Grimm and Rosen 2003) and distinct from the cuboidal luminal epithelial cells expressing Gata3 and Er $\alpha$ (Supplemental Fig. 2B). We investigated the temporal mRNA expression patterns of Elf5 and Gata3 in the $\mathrm{CD}^{+} 1^{+}$and $\mathrm{CD}^{-} 1^{-}$mammary cell populations collected from virgin, 12.5 -dpc, and 18.5-dpc mammary glands (Fig. 4G). We observed similar expression patterns of Elf5 and Gata3 within the $\mathrm{CD} 61^{+}$luminal progenitor populations in virgin and 12.5-dpc mammary glands. Quantitative PCR demonstrated that the expression of Gata3 was high in the $\mathrm{CD} 61^{-}$mature luminal population from virgin mice and decreased at $18.5 \mathrm{dpc}(9.8$ vs. 4.8, $P=0.02)$. In contrast, the expression of Elf5 was lower in the CD $61^{-}$mature luminal cells in virgins and increased at $18.5 \mathrm{dpc}(5.2$ vs. $10.2, P<0.01)$ (Fig. 4G). These data demonstrate that although Elf5 and Gata3 are both expressed within the $\mathrm{CD} 61^{+}$luminal progenitor cells, this population may be a heterogeneous population consisting of Gata3-responsive and Elf5-responsive progenitors, with the latter corresponding to the putative alveolar progenitor that gives rise to the secretory epithelium required for lactation.

Whether Elf5 and Gata3 act in concert within the same progenitor population resulting in differentiated alveolar epithelium remains to be determined. Furthermore, the dichotomy of expression of these two essential transcription factors in the mammary gland suggests a further complexity to mammary cell fate determination that remains to be understood. Cell surface markers that more adequately identify unique progenitor populations within the mammary cell hierarchy need to be identified before questions like these can be addressed. Here we show that the transcription factor Elf5 is a critical cell fate determinant for secretory alveolar epithelium, which induces differentiation during alveolar morphogenesis. These findings are the first description of a transcription factor that specifically determines alveolar cell fate.

\section{Materials and methods}

Mice

All experiments involving mice were performed under the supervision of and in accordance with the regulations of the Garvan/St. Vincent's Ani- mal Experimentation Committee. The MTB, Elf5-/-, and Elf5+/- mice were generated as described previously (Gunther et al. 2002; Donnison et al. 2005; Zhou et al. 2005). Elf5 $5^{-/}$epithelium was maintained by serial transplantation using techniques as described before (DeOme et al. 1959). Transgenic mice carrying the TetOn-Elf5-IRES-EGFP construct were generated by oocyte injection techniques (Ozgene) on an FVB/N background. Elf5 $\mathrm{Tg}^{E l+5 /+/ M T B /+}(\mathrm{Tg})$ mice were produced by breeding and were given $2: 50 \mathrm{mg} / \mathrm{mL}$ Dox:sucrose in their drinking water for a period of 1 or 3 wk. Mice were injected i.p. with $\mathrm{BrdU}$ dissolved in $\mathrm{H}_{2} \mathrm{O}(100 \mu \mathrm{g} \mathrm{BrdU}$ per gram body weight) $2 \mathrm{~h}$ prior to sacrifice by $\mathrm{CO}_{2}$ asphyxiation, and mammary glands were collected. Mammary glands were either wholemounted and stained with Carmine alum as described previously (Bradbury et al. 1995) or snap-frozen in liquid nitrogen for mRNA and protein analyses. Rag $1^{-1-}$ mice (Mombaerts et al. 1992) of the C57BL/6J strain were purchased from the Animal Resource Center, Perth, Australia. All animals were housed with food and water ad libitum with a 12-h day/ night cycle at $22^{\circ} \mathrm{C}$ and $80 \%$ relative humidity. $\operatorname{Rag}^{-1-}$ mice were administered Resprim (Alphapharm) containing Sulfamethoxazole/Trimethoprim via drinking water $(5 \mathrm{mg} / 1 \mathrm{mg}$ per $5 \mathrm{~mL}$ drinking water) in alternate weeks.

Tissue preparation, immunohistochemistry, and immunofluorescence Four-micron mammary gland sections were baked for $5 \mathrm{~min}$ at $80^{\circ} \mathrm{C}$ and placed in Xylene for deparaffinization. Antigen retrieval was performed using target retrieval solution low-pH (S1699) 20-min water bath ( $\alpha$-Milk, Accurate Chemical and Scientific Corp., NY) i, high-pH (S2367) 20-min water bath $(\alpha-\mathrm{BrdU})$ and pressure cooker (Gata3; Santa Cruz Biotechnology), low-pH (S1699) pressure cooker ( $\alpha$-Ki67; Labvision and Er $\alpha$ [M-20]; Santa Cruz Biotechnology), and high-pH (S3307) pressure cooker ( $\alpha$-Elf5 [N-20]; Santa Cruz) $\alpha$-Zol (Zymed Laboratories) and $\alpha$ - $\beta$ Catenin (BD Biosciences). For immunohistochemistry, slides were blocked in $3 \% \mathrm{H}_{2} \mathrm{O}_{2}$ prior to application of 1:12,000 $\alpha$-Milk, 1:100 $\alpha$-Ki67, 1:600 Elf5, 1:50 Gata3, or 1:100 $\alpha$-BrdU. Secondary antibodies were Envision rabbit $(\alpha-$ ki-67, $\alpha$-Milk) or Envision mouse ( $\alpha$-BrdU, $\alpha$-Gata3) applied for $30 \mathrm{~min}$ or 1:200 horse $\alpha$-goat (Vector Laboratories) followed by Streptavidin Label $\left(\alpha\right.$-Elf5). Visualization was via diaminobenzidine $\left(\mathrm{DAB}^{+}\right)$. All immunecytochemistry reagents were purchased from Dako Cytomation unless otherwise stated. For immunofluorescence, slides were blocked in $1 \%$ normal goat serum in phosphate-buffered saline for $1 \mathrm{~h}$, prior to application of $50 \mu \mathrm{L}$ of 1:600 $\alpha$-Elf5, 1:200 $\alpha$-Er $\alpha, 1: 100 \alpha$-Zol, and 1:200 $\alpha$ $\beta$ Catenin primary antibodies under a coverslip overnight at $4^{\circ} \mathrm{C}$. The sections were then incubated with secondary antibody 1:500 $\alpha$-mouse $\mathrm{Cy} 2, \alpha$-goat Cy3, and $\alpha$-rabbit Cy3 or Cy2 (Jackson ImmunoResearch) and 1:200 ToPro3 (Invitrogen) for $2 \mathrm{~h}$ at room temperature. Sections were cover-slipped in Confocal-Matrix (Micro-Tech-Lab).

\section{Quantitative PCR}

Total RNA was isolated using Trizol reagent according to the manufacturer's instructions (Gibco/Invitrogen Vic). Single-stranded cDNA was produced by reverse transcription using $1 \mu \mathrm{g}$ of RNA in a $20-\mu \mathrm{L}$ reaction and diluted 1:5 with $\mathrm{H}_{2} \mathrm{O}$ (Promega). Quantitative PCR was performed using the TaqMan probe-based system (Elf5 Mm00468732_ml, Gata3 Mm00484683_m1, $\beta$-casein Mm00839664_ml, Wap Mm00839913_ml, and Cytokeratin $18 \mathrm{Mm01601704 \_ g1)}$ on the ABI 7900HT as per the manufacturer's instructions (Applied Biosystems).

\section{Western blotting}

Protein (20 $\mu \mathrm{g}$ per lane) was separated using SDS-PAGE (Bio-Rad Laboratories), transferred to polyvinylidine difluoride (Millipore Corp.), and blocked overnight with $1 \%$ skim milk powder, $50 \mathrm{nM}$ sodium phosphate, $50 \mathrm{mM} \mathrm{NaCl}$, and $0.1 \%$ Tween 20 . Membranes were incubated with 1:5000 $\alpha$ - $\beta$-casein (gift of C Streuli, University of Manchester, United Kingdom), $\alpha$-phosphorylated p44/42 Mapk (pErk), $\alpha$-total p44/42 MapK (Erk) (Cell Signaling Technologies), and 1:40,000 $\alpha$ - $\beta$-actin (Sigma-Aldrich). Specific binding was detected using horseradish peroxidase-conjugated secondary antibodies (Amersham Briosciences) with Chemiluminescence Reagent (PerkinElmer) and Fuji Medical X-ray Film (Fujifilm).

MaSC and progenitor cell analysis and colony formation assay Mammary glands were dissected from $E 1 f^{+/+}$and $E l f 5^{+/-}$female mice or Elf5 $5^{+/+}$and Elf5 $5^{-/-}$transplants or Elf5Tg $\mathrm{Tg}^{E l f 5 /+/ M T B /+}$ and Elf5Tg $\mathrm{Tg}^{+/ / M T B /+}$ mice treated with Dox for 4 wk. Mammary epithelial cell suspensions were prepared as described previously (Shackleton et al. 2006; Asselin- 
Oakes et al.

Labat et al. 2007). Cells were stained with anti-CD31 and anti-CD45 antibodies conjugated to biotin (BD Pharmingen) or Qdot ${ }_{655}$ (Invitrogen), anti-CD24 conjugated to biotin or PE (BD Pharmingen), anti-CD29 conjugated to FITC or PE (Chemicon), and anti-CD61 conjugated to APC (Caltag) followed by streptavidin-APC-Cy7 (BD Pharmingen) or streptavidin-Alexa-594 (Molecular Probes). Cell sorting and analysis were carried out on a FACS ARIA or FACSDiVa (Becton Dickinson). Colonyforming assays were performed as described previously (Shackleton et al. 2006; Asselin-Labat et al. 2007). Briefly, freshly sorted cells were plated on irradiated feeders and treated with tetracycline ( $10 \mu \mathrm{g} / \mathrm{mL}$; Sigma) for $5 \mathrm{~d}$ to maintain the expression of the transgene. Cells were then fixed with acetone:methanol (1:1) and stained with Giemsa.

\section{Acknowledgments}

Financial Support was provided by the National Health and Medical Research Council, Cancer Council NSW, Cure Cancer Australia, Victorian Breast Cancer Research Consortium, Cancer Institute NSW, Australian Research Council, and CRC for Innovative Dairy Products.

\section{References}

Asselin-Labat, M.L., Sutherland, K.D., Barker, H., Thomas, R., Shackleton, M., Forrest, N.C., Hartley, L., Robb, L., Grosveld, F.G., van der Wees, J., et al. 2007. Gata-3 is an essential regulator of mammarygland morphogenesis and luminal-cell differentiation. Nat. Cell Biol. 9: 201-209.

Bradbury, J.M., Edwards, P.A., Niemeyer, C.C., and Dale, T.C. 1995. Wnt-4 expression induces a pregnancy-like growth pattern in reconstituted mammary glands in virgin mice. Dev. Biol. 170: 553-563.

Chilton, B.S. and Hewetson, A. 2005. Prolactin and growth hormone signaling. Curr. Top. Dev. Biol. 68: 1-23.

DeOme, K.B., Faulkin, L.J.J., Bern, H.A., and Blair, P.B. 1959. Development of mammary tumors from hyperplastic alveolar nodules transplanted into gland-free mammary fat pads of female C3H mice. Cancer Res. 19: 515-520.

Donnison, M., Beaton, A., Davey, H.W., Broadhurst, R., L'Huillier, P., and Pfeffer, P.L. 2005. Loss of the extraembryonic ectoderm in Elf5 mutants leads to defects in embryonic patterning. Development 132: 2299-2308.

Grimm, S.L. and Rosen, J.M. 2003. The role of C/EBP $\beta$ in mammary gland development and breast cancer. J. Mammary Gland Biol. Neoplasia 8: 191-204.

Gunther, E.J., Belka, G.K., Wertheim, G.B., Wang, J., Hartman, J.L., Boxer, R.B., and Chodosh, L.A. 2002. A novel doxycycline-inducible system for the transgenic analysis of mammary gland biology. FASEB J. 16: 283-292.

Harris, J., Stanford, P.M., Sutherland, K., Oakes, S.R., Naylor, M.J., Robertson, F.G., Blazek, K.D., Kazlauskas, M., Hilton, H.N., Wittlin, S., et al. 2006. Socs2 and Elf5 mediate prolactin-induced mammary gland development. Mol. Endocrinol. 20: 1177-1187.

Kordon, E.C. and Smith, G.H. 1998. An entire functional mammary gland may comprise the progeny from a single cell. Development $\mathbf{1 2 5}$ 1921-1930.

Kouros-Mehr, H., Slorach, E.M., Sternlicht, M.D., and Werb, Z. 2006. GATA-3 maintains the differentiation of the luminal cell fate in the mammary gland. Cell 127: 1041-1055.

Mombaerts, P., Iacomini, J., Johnson, R.S., Herrup, K., Tonegawa, S., and Papaioannou, V.E. 1992. RAG-1-deficient mice have no mature B and T lymphocytes. Cell 68: 869-877.

Neville, M.C., McFadden, T.B., and Forsyth, I. 2002. Hormonal regulation of mammary differentiation and milk secretion. J. Mammary Gland Biol. Neoplasia 7: 49-66.

Oettgen, P., Kas, K., Dube, A., Gu, X., Grall, F., Thamrongsak, U., Akbarali, Y., Finger, E., Boltax, J., Endress, G., et al. 1999. Characterization of ESE-2, a novel ESE-1-related Ets transcription factor that is restricted to glandular epithelium and differentiated keratinocytes. $J$. Biol. Chem. 274: 29439-29452.

Ormandy, C.J., Naylor, M., Harris, J., Robertson, F., Horseman, N.D., Lindeman, G.J., Visvader, J., and Kelly, P.A. 2003. Investigation of the transcriptional changes underlying functional defects in the mammary glands of prolactin receptor knockout mice. Recent Prog. Horm. Res. 58: 297-323.
Shackleton, M., Vaillant, F., Simpson, K.J., Stingl, J., Smyth, G.K., Asselin-Labat, M.L., Wu, L., Lindeman, G.J., and Visvader, J.E. 2006. Generation of a functional mammary gland from a single stem cell. $\mathrm{Na}$ ture 439: 84-88.

Smalley, M. and Ashworth, A. 2003. Stem cells and breast cancer: A field in transit. Nat. Rev. Cancer 3: 832-844.

Stingl, J., Eirew, P., Ricketson, I., Shackleton, M., Vaillant, F., Choi, D., Li, H.I., and Eaves, C.J. 2006. Purification and unique properties of mammary epithelial stem cells. Nature 439: 993-997.

Thomas, R.S., Ng, A.N., Zhou, J., Tymms, M.J., Doppler, W., and Kola, I. 2000. The Elf group of Ets-related transcription factors. ELF3 and ELF5. Adv. Exp. Med. Biol. 480: 123-128.

Zhou, J., Ng, A.Y., Tymms, M.J., Jermiin, L.S., Seth, A.K., Thomas, R.S., and Kola, I. 1998. A novel transcription factor, ELF5, belongs to the ELF subfamily of ETS genes and maps to human chromosome 11p1315 , a region subject to $\mathrm{LOH}$ and rearrangement in human carcinoma cell lines. Oncogene 17: 2719-2732.

Zhou, J., Chehab, R., Tkalcevic, J., Naylor, M.J., Harris, J., Wilson, T.J., Tsao, S., Tellis, I., Zavarsek, S., Xu, D., et al. 2005. Elf5 is essential for early embryogenesis and mammary gland development during pregnancy and lactation. $E M B O J$. 24: 635-644. 


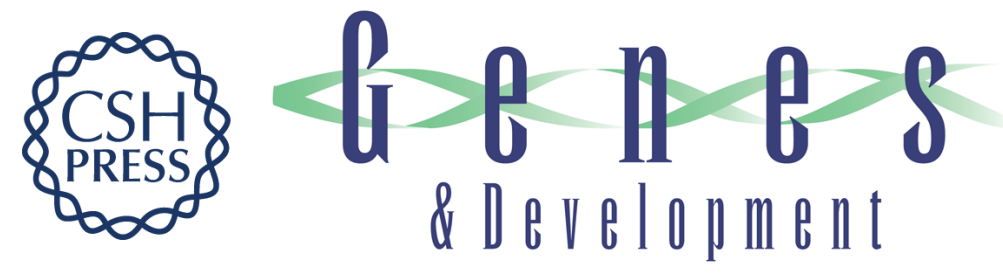

\section{The Ets transcription factor Elf5 specifies mammary alveolar cell fate}

Samantha R. Oakes, Matthew J. Naylor, Marie-Liesse Asselin-Labat, et al.

Genes Dev. 2008, 22:

Access the most recent version at doi:10.1101/gad.1614608

Supplemental

Material

References

This article cites 20 articles, 5 of which can be accessed free at: http://genesdev.cshlp.org/content/22/5/581.full.html\#ref-list-1

\section{License}

Email Alerting Service

http://genesdev.cshlp.org/content/suppl/2008/02/19/22.5.581.DC1 right corner of the article or click here.

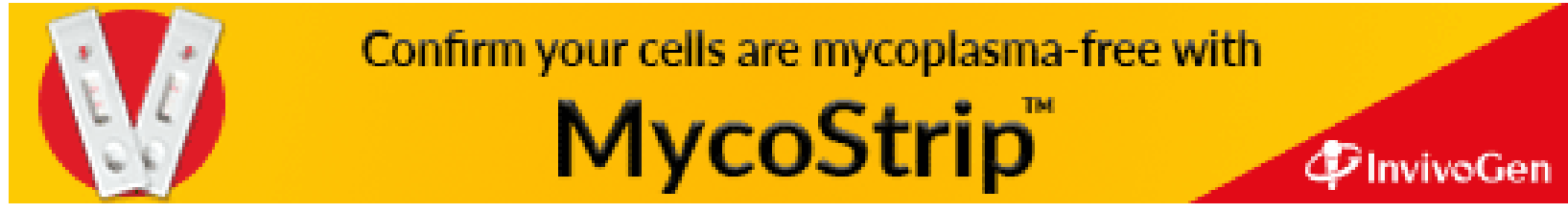

